\title{
Functionalisation of cross-linked polyethylenimine for the removal of As from mining wastewater
}

\author{
Dalia M Saad, Ewa M Cukrowska and Hlanganani Tutu* \\ Molecular Science Institute, School of Chemistry, University of the Witwatersrand, Private Bag X3, WITS 2050, Johannesburg, South Africa
}

\section{ABSTRACT}

\begin{abstract}
Cross-linked polyethylenimine (CPEI) was phosphonated by reaction with phosphorous acid and formaldehyde. The functionalised polymer was used as an adsorbent for the removal of arsenic as an oxo-anion. The binding affinity of the synthesised polymer to abstract As from synthetic solutions and wastewater samples was assessed, as well as its ability to be regenerated for re-use. The PCPEI demonstrated an elevated loading capacity, removing up to $88 \%$ of As. The kinetic rates were modelled using pseudo first-order and pseudo second-order equations. The pseudo second-order equation was found to explain the adsorption kinetics most effectively, implying chemisorption. The Langmuir and Freundlich isotherms were used to interpret the adsorption of As onto PCPEI. The Freundlich isotherm was found to best fit and describe the experimental data. The thermodynamic study of the adsorption process indicated high activation energies $\left(55.91 \mathrm{~kJ} \mathrm{~mol}^{-1}\right)$ which confirms chemisorption as a mechanism of interaction between As and PCPEI.
\end{abstract}

Keywords: Adsorption; arsenic; phosphonated cross-linked polyethylenimine, functionalisation

\section{INTRODUCTION}

Water pollution is an increasingly pressing problem. The world is facing a challenge in meeting rising demands for unpolluted water, since the available supplies of freshwater are decreasing due to population growth, extended droughts, extensive industrialisation and improper disposal. Water contamination by trace elements is a global environmental concern as it affects the quality of drinking water and hence human health. Although some elements are natural nutrients at trace level, they become very toxic at high concentrations. High concentrations of toxic elements result from intensive anthropogenic activities, including mining, agriculture, and disposal of industrial waste materials (Akpor and Muchie, 2010; Liu et al., 2008; Savage and Diallo, 2005; Ruparelia et al., 2008; Ahmed et al., 2008; Madoni and Giuseppa, 2005; Bhattacharya et al., 2007). Arsenic (As) is one of the most toxic elements. It is a naturally occurring metalloid and a micronutrient in small quantities. Elevation of As concentration in natural water is a major concern because of its toxicity, posing a threat to aquatic life if left untreated. Long-term drinking of arsenic-polluted water causes bladder, kidney, skin, and lung cancer, as well as other effects such as loss of appetite, muscular weakness, pigmentation changes, and nausea. Arsenic is mobilised naturally by weathering reactions, biological activity, geochemical reactions and volcanic emissions, as well as anthropogenic activities. Mining activities account for some of the most serious additional sources (Carvalho and Martin, 2001; Mohan and Pittman, 2007)

Several different methods have been reported to remove toxic elements from wastewaters, such as chemical-, physical-, and bio-remediation (Sauer et al., 2004). Among the remediation techniques for metal ion removal, polymeric adsorbents

\footnotetext{
To whom all correspondence should be addressed.

+27 11 717 6771; e-mail: Hlanganani.tutu@wits.ac.za Received 21 September 2012; accepted in revised form 25 March 2013.
}

are some of the more efficient in terms of technical and economic efficiency, feasibility, and environmental impact.

Polyethylenimine (PEI) is one of the most popular polymeric adsorbents and well-known for its metal-chelating properties (Leroy et al., 2003). It has been widely applied for the retention of toxic elements. PEI is more effective for the removal of metals than metalloids (Saad et al., 2011). The aim of this study, therefore, was to develop a water-insoluble form of polyethylenimine with suitable functionality to facilitate selective removal of As. The insoluble property of PEI was achieved by cross-linking, as reported in a previous study by the authors (Saad et al., 2011).

\section{MATERIALS AND METHODS}

\section{Materials}

All chemicals were obtained from Sigma Aldrich (South Africa) without further purification. Cross-linked polyethylenimine (Saad et al., 2011), phosphorous acid, formaldehyde $38 \%\left(\mathrm{CH}_{2} \mathrm{O}\right)$, and $6 \mathrm{~mol} \cdot \ell^{-1} \mathrm{HCl}$ were used. The solutions were prepared from $\mathrm{NaAsO}_{2}$. Adjustments of $\mathrm{pH}$ for the adsorption experiments were conducted using $1 \mathrm{~mol} \cdot \ell^{-1}$ solutions of $\mathrm{HNO}_{3}$ and $\mathrm{NaOH}$. Deionised water was used for the preparation of all solutions.

\section{Synthesis of PCPEI}

The synthesis of PCPEI was carried out according to the method reported by Saad et al. (2012a); cross-linked polyethylenimine, $2.5 \mathrm{~g}$, was placed in $80 \mathrm{~m} \ell$ of $6 \mathrm{~mol} \cdot \ell^{-1} \mathrm{HCl}$. Phosphorous acid, $19.31 \mathrm{~g}$, was added and the mixture was heated under reflux at $90^{\circ} \mathrm{C}$. Formaldehyde, $38 \mathrm{ml}$, was added drop-wise over a period of an hour, and the reaction was left overnight. A pale powdery yellow solid was obtained, and was washed with abundant deionised water before drying in an air oven at $30^{\circ} \mathrm{C}$. The solid was then pulverised and sieved. 


\section{Batch adsorption studies}

The batch adsorption experiments were conducted using a $1000 \mathrm{mg} \cdot \ell^{-1}$ standard stock solution of $\mathrm{NaAsO}_{2}$ from which the $40 \mathrm{mg} \cdot \ell^{-1}$ working standard solutions were obtained by serial dilution. Adsorption experiments were performed in $50 \mathrm{~m} \ell$ flasks at room temperature. $1 \mathrm{~g}$ of synthetic PCPEI (an optimal adsorbent amount according to preliminary optimisation of the solid: liquid ratio) was weighed out into each flask separately; $40 \mathrm{~m} \ell$ of $40 \mathrm{mg} \cdot \ell^{-1}$ standard solutions were then added to each flask and stirring done by means of magnetic stirrer. This concentration was arbitrarily chosen as it represents a 'worst-case' scenario of pollution by most toxic elements (e.g. Hg, U, As and V) in mining-impacted waters in the Witwatersrand Basin goldfields (Tutu et al., 2009). Adsorption at $\mathrm{pH} 3$ and $\mathrm{pH} 8$ was assessed to investigate the effect of $\mathrm{pH}$. At equilibrium, the solutions were filtered and the equilibrium concentrations determined using a Genesis inductively coupled plasma optical emission spectroscopy (ICP-OES) (Spectro, Germany). The amount of ions adsorbed per unit mass of adsorbent was calculated on the basis of the mass balance equation:

$$
\text { Capacity (mg metal.g } \left.{ }^{-1} \text { polymer }\right)=\frac{\left(C_{i}-C_{f}\right) \times V}{1000 \times P}
$$

where:

$C_{i}\left(\mathrm{mg} \cdot \ell^{-1}\right)$ is the initial concentration of As in the solution $C_{f}\left(\mathrm{mg} \cdot \ell^{-1}\right)$ is the concentration of As in the filtrate

$V(\mathrm{~m} \ell)$ is the volume of initial solution

$P(\mathrm{~g})$ is the amount of polymer used.

\section{Effect of contact time}

Adsorption experiments were conducted at room temperature in order to obtain the optimal time required for adsorption. Adsorption was studied at various time intervals (10-120 min) and fixed concentration $\left(40 \mathrm{mg} \cdot \ell^{-1}\right)$. The concentration of As was determined at the end of each time period. The obtained equilibrium capacities $\left(q_{e}\right)$ were then plotted against the equilibrium time for kinetic modelling.

\section{Desorption studies}

The regeneration of the synthesised polymer was carried out by the treatment of previously loaded polymer with an excess of extracting reagent. $\mathrm{HNO}_{3}$ at different concentrations, namely, $2 \mathrm{~mol} \cdot \ell^{-1}, 3 \mathrm{~mol} \cdot \ell^{-1}, 5 \mathrm{~mol} \cdot \ell^{-1}$, and $7 \mathrm{~mol} \cdot \ell^{-1}$, was used as an extractant. During regeneration, the mixtures were stirred for $1 \mathrm{~h}$, filtered and the polymer washed with de-ionised water and dried prior to re-use.

\section{Application of the developed polymer to wastewater samples}

The synthesised polymer was applied for the removal of As from wastewater samples collected in the vicinity of goldmining activities in the Central Rand Goldfield, Johannesburg.

Five samples were used (1 pit water and 4 surface water samples) collected from the Natalspruit, an acid mine drainage impacted stream (26 $13^{\prime} 07.15^{\prime \prime} \mathrm{S}$ and $\left.28^{\circ} 07^{\prime} 52.74^{\prime \prime} \mathrm{E}\right)$. Sampling was done according to standard water sampling protocols (Hermond and Fechner-Levy, 2000) and geochemical parameters $(\mathrm{pH}$, redox potential and electrical conductivity) recorded in the field using field-meters. The samples were filtered in the laboratory prior to application in the adsorption experiments. The field measurements were carried out with a portable kit Multi Line F/Set 3 of the Wissenschaftlich- Technische Werkstatten, Weilheim (WTW, Germany) equipped with a $\mathrm{pH}$ electrode, an integrated temperature probe (Sen Tix 41), a standard conductivity cell (Tetra Con 375) and an oxidation-reduction potential probe (Sen Tix ORP). The $\mathrm{pH}$ electrode was calibrated according to IUPAC recommendations against 2 buffer solutions, $\mathrm{pH} 4$ and $\mathrm{pH} 7$, and with an uncertainty of \pm 0.1 units. Metal analysis was carried out using ICP-OES. Anion concentrations were determined by ion chromatography (IC) (761 Compact, Metrohm, Switzerland).

In each analytical technique, the limit of detection (LOD) was calculated as $3 \mathrm{x}$ standard deviation of the blank and the method quantitation limit (MQL) was calculated as $10 \mathrm{x}$ standard deviation of the blank.

\section{Modelling of analytical results}

The results from adsorption studies were modelled using kinetic, equilibrium (isotherms), and thermodynamic models.

\section{Kinetic models}

The kinetic models that were used to fit the experimental data were as follows:

The pseudo first-order model was defined by the equation:

$$
\log \left(q_{e}-q_{t}\right)=\log q_{e}-\left(k_{1} / 2.303\right) \mathrm{t}
$$

The plot of $\log \left(q_{e}-q_{t}\right)$ vs. $t$ gives a straight line.

The pseudo second-order model was defined by the equation:

$$
1 / q_{t}=\left(1 / k_{2} q_{e}^{2}\right)+\left(1 / q_{e}\right) t
$$

The plot of $t / q_{t}$ vs. $t$ gives a straight line.

The parameters in the above equations are defined as follows: $q_{e}\left(\mathrm{mg} \cdot \mathrm{g}^{-1}\right)$ is the adsorption capacity at equilibrium, $q_{t}\left(\mathrm{mg}^{-1}\right)$ is the adsorption capacity at time $t$, and $k_{1}$ and $k_{2}$ $(1 / \mathrm{min})$ are the rate constants for the pseudo first-order and pseudo second-order models, respectively. These are obtained from the slope of the plot of $\log \left(q_{e}-q_{t}\right)$ vs $t$.

The experimental data for kinetic modelling were obtained by conducting the adsorption experiments using $1 \mathrm{~g}$ of PCPEI and $40 \mathrm{~m} \ell$ of $40 \mathrm{mg} \cdot \ell^{-1}$ standard solutions at different time intervals under continuous stirring at $\mathrm{pH} 3$.

\section{Isotherm models}

Adsorption isotherms describe the nature of the adsorbentadsorbate interaction as well as the specific relation between the concentration of adsorbate and its degree of accumulation onto the adsorbent surface (Gupta et al., 2003; Li et al., 2008). In order to understand the adsorption mechanism of As onto the PCPEI surface, two adsorption isotherm models, Langmuir and Freundlich, were used to fit the experimental data. The experimental data for isotherm modelling were obtained by conducting the adsorption experiments using $1 \mathrm{~g}$ of PCPEI and $40 \mathrm{~m} \ell$ solutions of different As concentrations under continuous stirring. At equilibrium, the solutions were filtered and the non-desorbed arsenic was determined. 


\section{Langmuir model}

The Langmuir model is valid for monolayer localised physical adsorption onto a homogeneous surface with a finite number of identical sites. In monolayer adsorption, there is no transmigration of adsorbed molecules at the maximum adsorption, meaning that the adsorbed molecules do not deposit on each other, but are only adsorbed on the free surface of the adsorbent (Hamdaoui and Naffrechoux, 2007). The Langmuir model is given by the following equation:

$$
q_{e}=\frac{q_{m} b C_{e}}{1+b C_{e}}
$$

where:

$q_{e}\left(\mathrm{mg} \mathrm{g}^{-1}\right)$ is the amount adsorbed per unit weight of adsorbent at equilibrium

$C_{e}\left(\mathrm{mg} \cdot \mathrm{\ell}^{-1}\right)$ is the equilibrium concentration of the adsorbate

$q_{m}\left(\mathrm{mg} \mathrm{g}^{-1}\right)$ is the maximum adsorption capacity

$b\left(\ell \cdot \mathrm{mg}^{-1}\right)$ is the constant related to the free energy of adsorption.

The values of maximum capacity $\left(q_{m}\right)$ and Langmuir constant (b) were calculated from the intercept and the slope of the plots.

\section{Freundlich model}

The Freundlich model is an empirical formula for heterogeneous adsorption given by the following equation:

$$
q_{e}=K_{F} C_{e}^{1 / n}
$$

where:

$$
K_{F}\left(\mathrm{mg}^{1-(1 / n)} \ell^{1 / n} \mathrm{~g}^{-1}\right) \text { is a constant correlated to the relative }
$$
adsorption capacity of the adsorbent

$n$ is a constant indicative of the intensity of the adsorption.

Since the Freundlich model is an exponential equation, it assumes that the adsorption capacity of the adsorbent increases with increasing concentration of the adsorbate. The values $K_{F}$ and $1 / n$ can be correlated to the adsorption capacity and intensity (Freundlich, 1926).

\section{Thermodynamic modelling}

The thermodynamic study was done by conducting the adsorption experiments using the abovementioned procedure at 2 different temperatures $\left(15^{\circ} \mathrm{C}\right.$ and $\left.27^{\circ} \mathrm{C}\right)$. The concentrations obtained after adsorption were then used to calculate the activation energy $(E a)$ according to the Arrhenius equation:

$$
E_{a}=\frac{R \cdot T_{1} \cdot T_{2} \cdot \ln K_{2} / K_{1}}{T_{1}-T_{2}}
$$

where:

$$
\begin{aligned}
& E_{a} \text { is the activation energy } \\
& R \text { is the gas constant } \\
& T_{1} \text { and } T_{2} \text { are the two different temperatures } \\
& K_{1} \text { and } K_{2} \text { are constants for the two temperatures. }
\end{aligned}
$$

The constants $K_{1}$ and $K_{2}$ could be calculated as follows:

$$
K=\frac{C_{i}-C_{e} / M}{C_{e}}
$$

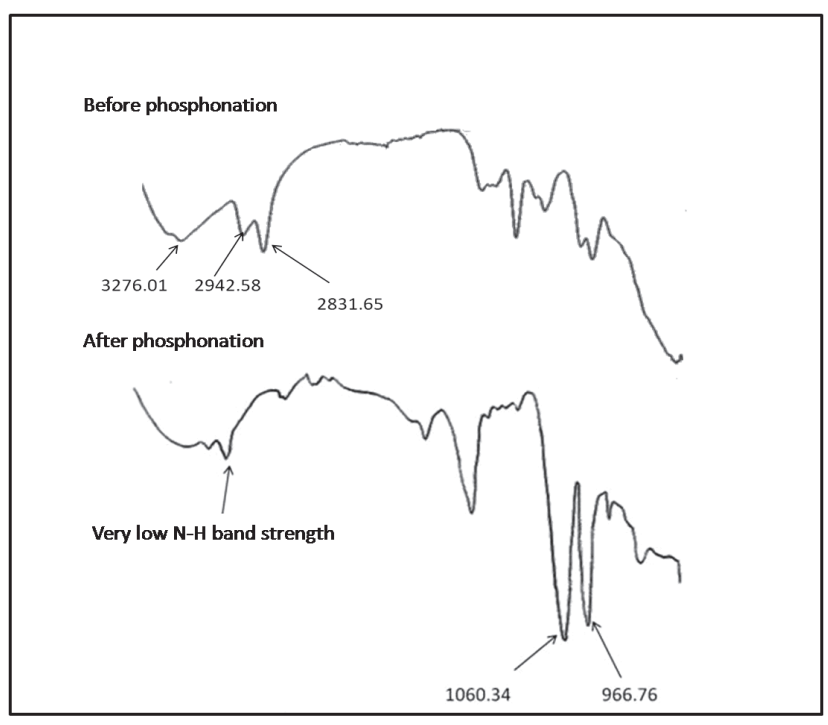

Figure 1

FTIR spectrum of CPEI and PCPEI

where:

$$
\begin{aligned}
& C_{i} \text { is the initial concentration }\left(\mathrm{mg} \cdot \ell^{-1}\right) \\
& C_{e}\left(\mathrm{mg} \cdot \ell^{-1}\right) \text { is the concentration at equilibrium for each } \\
& \text { temperature } \\
& M \text { is the atomic mass for each element. }
\end{aligned}
$$

The magnitude of the activation energy gives an indication of the type of adsorption. There are two main types of adsorption: chemisorption and physisorption. Physisorption is usually rapidly attained and easily reversible, because of the small amount of energy required, usually no more than $4.2 \mathrm{~kJ} \cdot \mathrm{mol}^{-1}$ since the forces involved are weak. Chemisorption involves much stronger forces and the activation energy is therefore higher (Klekamp and Urnbac, 1993; Özcan et al., 2006).

\section{RESULTS AND DISCUSSION}

\section{Characterisation of phosphonated cross-linked polyethylenimine}

Fourier transform infrared spectroscopy was used to characterise the phosphonated derivative of cross-linked polyethylenimine (PCPEI) in order to confirm the introduction of the $-\mathrm{PO}_{3} \mathrm{H}_{2}$ chelating group. The FTIR spectrum is given in Fig. 1.

The major peaks of importance on the IR spectrum of PCPEI are: $966.76 \mathrm{~cm}^{-1}$ indicating the presence of $\mathrm{P}-\mathrm{OH}$ bond; $1060.34 \mathrm{~cm}^{-1}$ corresponding to the presence of the $\mathrm{P}-\mathrm{O}$ bond; and $2803.31 \mathrm{~cm}^{-1}$ signifying the presence of the $\mathrm{PO}-\mathrm{H}$ bond. The difference in absorption band strength for the stretching vibration of $\mathrm{N}-\mathrm{H}$ before and after the phosphonation could be observed, with the phosphonated polymer yielding lower band strength. This could be attributed to the closure of some secondary amine sites during phosphonation of the polymer. The phosphonated polymer thus contains fewer secondary amine groups due to the reaction between these groups in CPEI and $\left(-\mathrm{PO}_{3} \mathrm{H}_{2}\right)$ groups in phosphorous acid.

\section{Effect of contact time}

Figure 2 shows the effect of contact time on the adsorption of As onto PCPEI. 


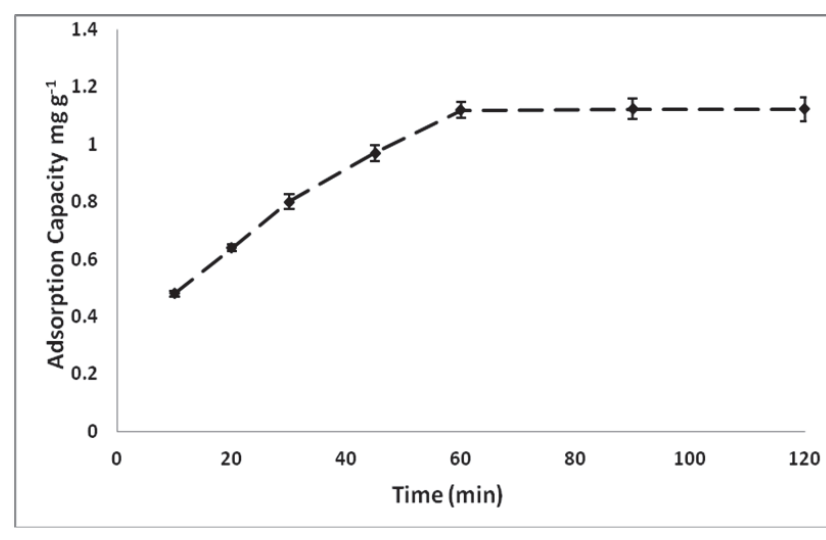

Figure 2

Effect of contact time on the adsorption process

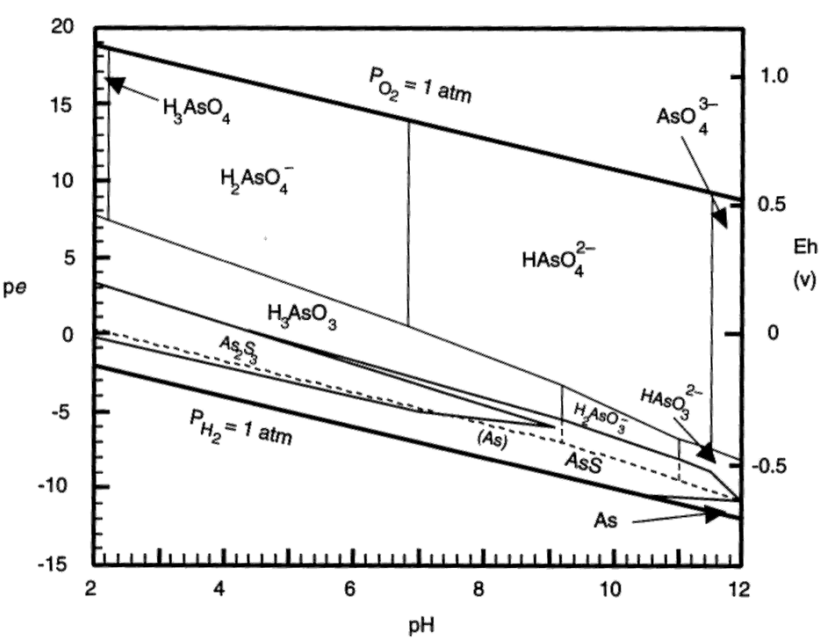

Figure 3

Pourbaix diagram for As

The adsorption was rapid within the first $30 \mathrm{~min}$, slowing down between 30-60 min and with no further increase beyond $60 \mathrm{~min}$. This could be attributed to the unavailability of reaction sites, as availability decreases with time. Thus, despite the increase in adsorption after $45 \mathrm{~min}$ being low, the minimum required time for adsorption to be completed was $60 \mathrm{~min}$.

\section{Effect of pH}

The results for the adsorption of As by PCPEI from synthetic solutions are presented in Table 1 . The table shows the final concentrations obtained $\left(C_{f}\right)$ after $60 \mathrm{~min}$, adsorption capacity, percentage as well as the relative standard deviation (RSD).

The adsorption percentages showed high removal efficiency. Moreover, the performance of PCPEI in removal of As was found to be independent of the $\mathrm{pH}$. As can be seen from the Pourbaix diagram (Fig. 3), As in aqueous systems is soluble across a wide $\mathrm{pH}$ range (2-12), as $\mathrm{H}_{2} \mathrm{AsO}_{4}$ and $\mathrm{HAsO}_{4}^{2-}$.

\section{Effect of initial concentration}

The results for the dependence of adsorption of As onto PCPEI on initial concentration are given in Fig. 4.

The adsorption increased with increasing concentration. It should be noted that, at each concentration, adsorption

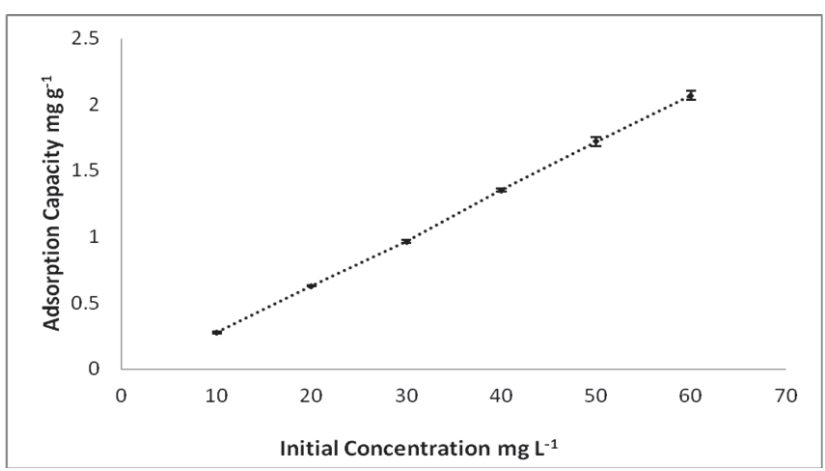

Figure 4

Effect of initial concentration on the adsorption process

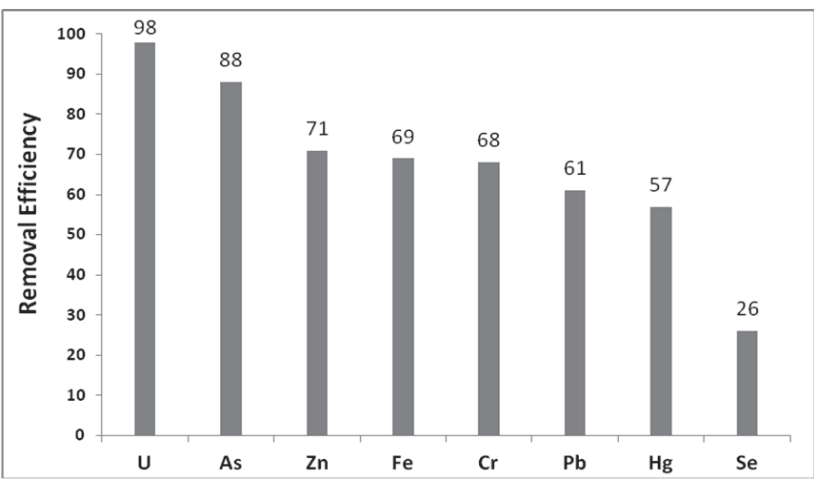

Figure 5

Removal efficiency for elements in a multi-component solution (at $R S D<10 \%$ )

\begin{tabular}{|c|c|c|c|c|}
\hline \multicolumn{5}{|c|}{$\begin{array}{c}\text { TABLE } 1 \\
\text { Removal of As from single-component synthetic solution } \\
\text { by PCPEI }\end{array}$} \\
\hline & $\begin{array}{c}C_{f} \\
\left(\mathrm{mg} \cdot \ell^{-1}\right)\end{array}$ & RSD & $\begin{array}{c}\text { Adsorption } \\
\text { capacity }\left(\mathrm{mg} \cdot \mathrm{g}^{-1}\right)\end{array}$ & $\begin{array}{c}\text { Adsorption } \\
\text { efficiency (\%) }\end{array}$ \\
\hline $\mathrm{pH} 3$ & 4.97 & 0.226 & 1.401 & $88 \%$ \\
\hline $\mathrm{pH} 8$ & 4.71 & 0.786 & 1.412 & $88 \%$ \\
\hline
\end{tabular}

Initial concentration of the ions $=40 \mathrm{mg} \cdot \ell^{-1} ; C_{f}-$ final concentration after adsorption; $R S D$ - relative standard deviation $(n=3)$; $L O D$ - limit of detection in $m g \cdot \ell^{-1}=0.018 ; M Q L-$ method quantitation limit in $m g \cdot \ell^{-1}=0.06$

increases and reaches a maximum after $60 \mathrm{~min}$, as shown in Fig. 2.

\section{Effect of competing ions}

To investigate the possibility of competition between As and other ions such as $\mathrm{Pb}, \mathrm{U}, \mathrm{Zn}, \mathrm{Fe}, \mathrm{Cr}, \mathrm{Hg}$, and Se, the adsorption experiments were performed using multi-component standard solutions of $40 \mathrm{mg} \cdot \ell^{-1}$ at $\mathrm{pH}$ 3. The amount of As adsorbed in the presence of these ions was determined to investigate the selectivity of PCPEI toward As. Figure 5 shows the removal efficiency of As in the presence of these elements.

PCPEI showed a similar performance to that observed in the single-component solution (88\%) which indicates that PCPEI displays a high efficiency in removing arsenic even in the presence of competing ions. The high selectivity of PCPEI 


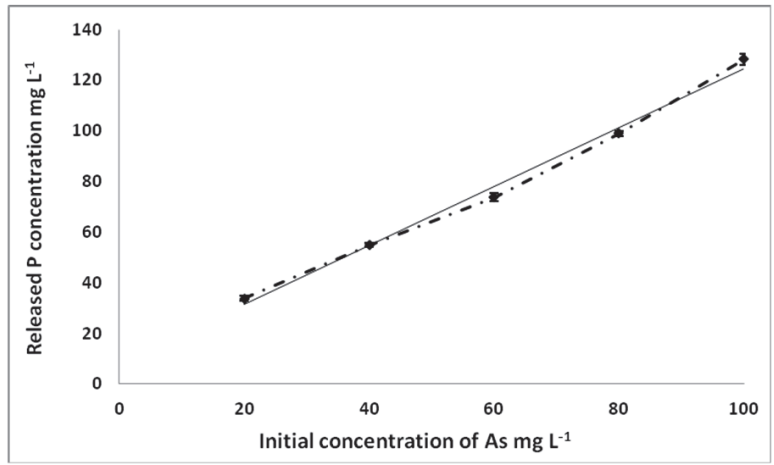

Figure 6

As concentration versus $P$ concentration

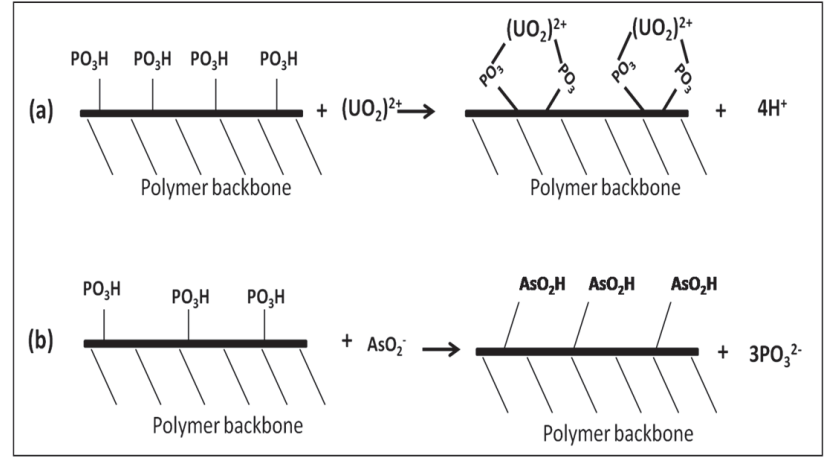

Figure 7

The mechanism of $U$ removal (a) and As removal (b) by PCPEI

towards As could be attributed to the functional group in the polymer. For example, in the previous study by the authors on cross-linked polyethylenimine (CPEI) (Saad et al., 2011), nitrogen was a donor atom and CPEI exhibited low removal of As especially in the presence of competing ions, where the removal percentage was $54 \%$. Another study by the authors (Saad et al., 2012b) where sulphur was the donor atom, also resulted in poor removal of As compared to other elements like Se and Hg. This confirms the role of the functionality of the polymer in selectivity behaviour and introduces the phosphate group as a most suitable functional group for removal of As. The results also showed that PCPEI has high affinity towards U; as such, $U$ is highly competitive against As. However, the removal mechanism is completely different, taking into account the fact that As is a metalloid whereas $U$ and the other elements (except Se) are metals. The mechanism of metal binding onto the polymer is based on the hard-soft Lewis acid-base theory, in which the $\mathrm{P}$ atom on the chelating group $\left(-\mathrm{PO}_{3} \mathrm{H}\right)$ acts as a Lewis base and donates electrons to metals which are Lewis acids. According to this mechanism, the high removal achieved for $\mathrm{U}$ is understandable since $\mathrm{U}$ is a hard acid and $\mathrm{P}$ a hard base.

To investigate the mechanism of As removal, the concentration of $\mathrm{P}$ was measured before and after adsorption. Figure 6 shows the concentration of the released $\mathrm{P}$ versus the initial concentration of As.

The increase of $\mathrm{P}$ concentration with the increase of As adsorption indicates the mechanism of As removal to be substitution of $\mathrm{HPO}_{3}$, because of the group similarities between As and P. Metals, e.g., $U$, are removed via interaction with the phosphate group on the polymer (complexation). Thus, the chemisorption adsorption of As is by reaction of As with the polymer backbone,

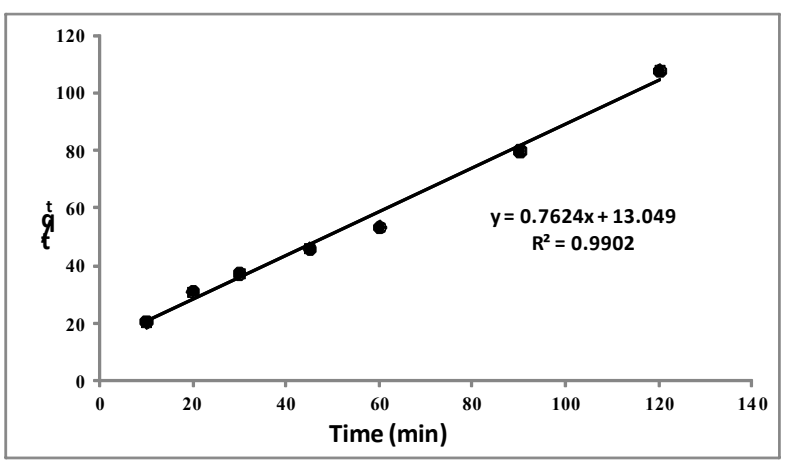

Figure 8

Pseudo second-order plot for the adsorption process

TABLE 2
\begin{tabular}{|c|c|c|c|c|c|c|}
\hline \multicolumn{2}{|c|}{ Langmuir and Freundlich parameters for the adsorption } \\
of As onto PCPEI \\
\hline & \multicolumn{3}{|c|}{ Langmuir } & \multicolumn{3}{c|}{ Freundlich } \\
\hline & $\boldsymbol{b}$ & $\boldsymbol{R}^{\mathbf{2}}$ & $\boldsymbol{q}_{m}$ & $\boldsymbol{K}_{f}$ & $\boldsymbol{R}^{\mathbf{2}}$ & $\mathrm{n}$ \\
\hline $\mathrm{pH} 3$ & 0.749 & 0.824 & 13.88 & 3.575 & 0.981 & 0.483 \\
\hline
\end{tabular}

while that for $\mathrm{U}$ is a metal-ligand complexation process $\left(\mathrm{U}-\mathrm{HPO}_{3} \mathrm{H}\right)$. Figure 7 demonstrates this mechanism.

Since As exists as a base in solutions, anion replacement could occur. Because As is in the same group in the periodic table as $\mathrm{P}$, they share some similarity in their chemical behaviour. This similarity allows them to replace each other (the As adsorbed onto the polymer surface and $\mathrm{P}$ released into the solution). Unlike the complexation reaction, protonation at low $\mathrm{pH}$ in this case does not affect chemical replacement.

\section{Kinetic modelling of adsorption process}

The high correlation obtained by plotting the linearised form of the pseudo second-order model $\left(R^{2}=0.990\right)$ when compared to that of pseudo first-order model $\left(R^{2}=0.756\right)$ demonstrated that pseudo second-order gives the best fit, implying that the adsorption occurs via a chemisorption process (Antures et al. 2003). A plot of the linearised form of pseudo second-order model (t/qt vs. $t)$ is given in Fig. 8 .

\section{Adsorption isotherms}

The calculated Langmuir constants $\left(b\right.$ and $\left.q_{m}\right)$ and Freundlich constants $\left(n\right.$ and $\left.K_{f}\right)$ as well as the coefficients of correlation $\left(R^{2}\right)$ for both isotherms are given in Table 2.

The results suggest that the Freundlich model best fits the data as shown by the correlation coefficient of $>0.95$, whereas that for the Langmuir correlation coefficient is $<0.95$. This result demonstrates adsorption on a heterogeneous surface. It also assumes that the adsorption capacity of the adsorbent increases with increasing concentration of the adsorbate, which is in agreement with the results obtained for the effect of initial concentration on adsorption.

\section{Thermodynamic studies}

The calculated activation energy value $\left(E_{a}\right)$ for the adsorption of As onto PCPEI surface as well as the calculated constants $K_{1}$ 
TABLE 3

Activation energy for the adsorption of Se by PCPEI

\begin{tabular}{|c|c|c|}
\hline$K_{1}$ & $K_{2}$ & $E a ~ k J \cdot$ mol $^{-1}$ \\
\hline 0.011 & 0.008 & 55.91 \\
\hline
\end{tabular}

TABLE 4

Removal of As from single-component synthetic solution by regenerated PCPEI

\begin{tabular}{|c|c|c|c|}
\hline $\begin{array}{c}\text { Cf } \\
\left(\mathrm{mg} \cdot \ell^{-1}\right)\end{array}$ & RSD & $\begin{array}{c}\text { Adsorption capacity } \\
\left(\mathrm{mg}^{-1} \mathbf{g}^{-1}\right.\end{array}$ & $\begin{array}{c}\text { Adsorption efficiency } \\
(\%)\end{array}$ \\
\hline 10.61 & 1.983 & 1.176 & $73 \%$ \\
\hline
\end{tabular}

Initial concentration of the ions $=40 \mathrm{mg} \cdot \ell^{-1} ; C_{f}$ - final concentration after adsorption; $R S D$ - relative standard deviation $(n=3) ; L O D$ - limit of detection in $\mathrm{mg} \cdot \ell^{-1}=0.003 ; M Q L-$ method quantitation limit in $\mathrm{mg} \cdot \ell^{-1}$ $=0.010$

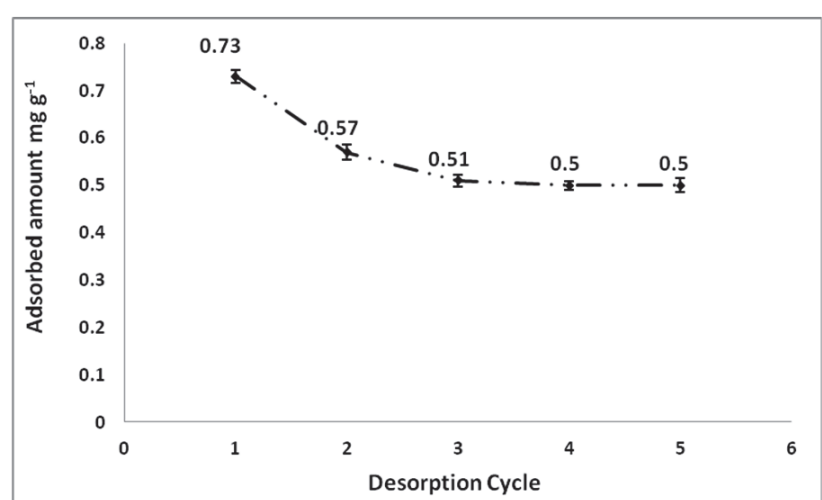

Figure 9

Desorption cycle of As from PCPEl using $7 \mathrm{~mol} \cdot \ell^{-1} \mathrm{HNO}$

\begin{tabular}{|c|c|c|c|c|c|c|}
\hline \multicolumn{7}{|c|}{$\begin{array}{c}\text { TABLE } 5 \\
\text { Removal of As from mining wastewater samples }\end{array}$} \\
\hline Samples & Metals & $C_{i}\left(\mathrm{mg} \cdot \mathrm{\ell}^{-1}\right)$ & $\operatorname{RSD}(n=3)$ & $C_{f}\left(\mathrm{mg} \cdot \ell^{-1}\right)$ & $\operatorname{RSD}(n=3)$ & Ads $\%$ \\
\hline \multirow{4}{*}{$\begin{array}{l}\text { SW } 1 \\
\text { pH }(3.8) \\
\mathrm{SO}_{4}^{-2}\left(383.2 \mathrm{mg} \cdot \ell^{-1}\right)\end{array}$} & $\mathrm{Fe}$ & 6.10 & 0.09 & 1.62 & 5.507 & $73 \%$ \\
\hline & $\mathrm{Ni}$ & 6.00 & 7.00 & 0.83 & 1.885 & $86 \%$ \\
\hline & $\mathrm{Zn}$ & 4.30 & 9.87 & 1.22 & 3.487 & $72 \%$ \\
\hline & $\mathrm{Mn}$ & 111.70 & 3.78 & 17.08 & 1.956 & $85 \%$ \\
\hline \multirow{3}{*}{$\begin{array}{l}\text { SW } 2 \\
\mathrm{pH}(7.2) \\
\mathrm{SO}_{4}^{-2}\left(19.80 \mathrm{mg} \cdot \ell^{-1}\right)\end{array}$} & As & 0.12 & 2.59 & 0.02 & 2.946 & $83 \%$ \\
\hline & $\mathrm{Se}$ & 0.09 & 5.84 & 0.06 & 5.456 & $14 \%$ \\
\hline & $\mathrm{Ni}$ & 1.50 & 5.28 & 0.37 & 2.164 & $75 \%$ \\
\hline \multirow{6}{*}{$\begin{array}{l}\mathrm{SW} 3 \\
\mathrm{pH}(4) \\
\mathrm{SO}_{4}^{-2}\left(819.4 \mathrm{mg} \cdot \ell^{-1}\right)\end{array}$} & $\mathrm{Cr}$ & 0.25 & 6.89 & 0.11 & 1.458 & $56 \%$ \\
\hline & As & 0.28 & 2.06 & 0.02 & 6.245 & $91 \%$ \\
\hline & $\mathrm{Fe}$ & 4.48 & 6.51 & 1.38 & 2.056 & $69 \%$ \\
\hline & $\mathrm{Ni}$ & 1.79 & 1.72 & 0.86 & 1.387 & $57 \%$ \\
\hline & $\mathrm{Zn}$ & 1.57 & 5.02 & 0.51 & 1.585 & $67 \%$ \\
\hline & $\mathrm{Mn}$ & 22.00 & 8.82 & 3.36 & 2.395 & $85 \%$ \\
\hline \multirow{4}{*}{$\begin{array}{l}\mathrm{SW} 4 \\
\mathrm{pH}(5.6) \\
\mathrm{SO}_{4}^{-2}\left(653.6 \mathrm{mg} \cdot \ell^{-1}\right)\end{array}$} & $\mathrm{Fe}$ & 5.84 & 8.97 & 1.50 & 6.765 & $74 \%$ \\
\hline & $\mathrm{Ni}$ & 4.67 & 3.53 & 0.88 & 2.061 & $81 \%$ \\
\hline & $\mathrm{Zn}$ & 7.65 & 7.07 & 1.76 & 2.078 & $77 \%$ \\
\hline & As & 7.34 & 2.09 & 0.87 & 1.92 & $88 \%$ \\
\hline \multirow{7}{*}{$\begin{array}{l}\text { Pit water } \\
\mathrm{pH}(3) \\
\mathrm{SO}_{4}^{-2}\left(1669 \mathrm{mg} \cdot \ell^{-1}\right)\end{array}$} & $\mathrm{Cr}$ & 0.04 & 7.75 & 0.02 & 2.395 & $61 \%$ \\
\hline & $\mathrm{Fe}$ & 0.60 & 3.54 & 0.14 & 3.707 & $77 \%$ \\
\hline & $\mathrm{Hg}$ & 0.28 & 1.84 & 0.12 & 1.817 & $56 \%$ \\
\hline & $\mathrm{Ni}$ & 10.70 & 7.97 & 2.03 & 1.860 & $81 \%$ \\
\hline & $\mathrm{U}$ & 0.16 & 6.70 & 0.001 & 5.048 & $99 \%$ \\
\hline & As & 0.89 & 1.31 & 0.10 & 0.564 & $89 \%$ \\
\hline & $\mathrm{Se}$ & 0.05 & 8.66 & 0.03 & 1.304 & $30 \%$ \\
\hline
\end{tabular}

$S W$ - surface water, $C_{i}$ - initial concentration before adsorption, $C_{f}$ - final concentration after adsorption.

LOD $\left(m g \cdot \ell^{-1}\right): C r-0.003 ; \mathrm{As}-0.014 ; \mathrm{Fe}-0.002 ; \mathrm{Hg}-0.001 ; \mathrm{Ni}-0.007 ; \mathrm{Zn}-0.008 ; \mathrm{Mn}-0.002 ; \mathrm{U}-0.035 ; \mathrm{Pb}-0.065$;

$\mathrm{Se}-0.017 ; \mathrm{SO}_{4}{ }^{2-}-0.01$ (by ion chromatography).

$\mathrm{MQL}\left(m g \cdot \ell^{-1}\right): \mathrm{Cr}-0.010 ; \mathrm{As}-0.047 ; \mathrm{Fe}-0.007 ; \mathrm{Hg}-0.003 ; \mathrm{Ni}-0.023 ; \mathrm{Zn}-0.027 ; \mathrm{Mn}-0.007 ; \mathrm{U}-0.117 ; \mathrm{Pb}-0.217$;

$\mathrm{Se}-0.057 ; \mathrm{SO}_{4}^{2-}-0.03$ (by ion chromatography).

and $K_{2}$ are presented in Table 3 .

The elevated value of activation energy implies As is adsorbed onto the PCPEI via a chemisorption process. This is consistent with the results obtained for kinetic modelling as discussed previously.

\section{Desorption studies}

Optimal recovery and regeneration of PCPEI was achieved at a concentration of $7 \mathrm{~mol} \cdot \ell^{-1}$ of the regeneration acid solution $\left(\mathrm{HNO}_{3}\right)$. Subsequently, regeneration of the used polymer was 
carried out using $40 \mathrm{~m} \ell$ of $7 \mathrm{~mol} \cdot \ell^{-1}$ acid. The adsorption efficiency for the recovered PCPEI with the same synthetic solutions is given in Table 4 .

Adsorption efficiency, though lower than that for the fresh polymer, still indicated good recovery. The adsorption efficiency dropped by $15 \%$.

Serial desorption was conducted in order to assess the amount of intractable As that would remain bound to the polymer. For example, after a cycle of 5 desorptions (Fig. 9), the adsorbed amount of As onto PCPEI dropped by $0.912 \mathrm{mg} \cdot \mathrm{g}^{-1}$ (from $1.412 \mathrm{mg} \cdot \mathrm{g}^{-1}$ to $0.5 \mathrm{mg} \cdot \mathrm{g}^{-1}$ after the fifth desorption).

\section{Application of the developed polymer to wastewater samples}

The results for the adsorption of As and other elements in the collected samples onto fresh PCPEI are given in Table 5.

The adsorption trend of As onto PCPEI was similar to that observed for the synthetic solutions. The removal order was $\mathrm{U}>\mathrm{As}>\mathrm{Mn}>\mathrm{Ni}>\mathrm{Zn}>\mathrm{Fe}>\mathrm{Hg}>\mathrm{Se}$.

\section{CONCLUSIONS}

In this study PCPEI was successfully employed for the removal of As under optimal conditions (contact time of $60 \mathrm{~min}$, initial concentration of $40 \mathrm{mg} \cdot \ell^{-1}$, and adsorbent amount of $1 \mathrm{~g}$ ). The removal mechanism hinges on the existence of the chelating group present in the PCPEI; largely, the $-\mathrm{PO}_{3} \mathrm{H}$ which facilitates the removal of oxo-anions. PCPEI exhibited commendable potential for re-use through regeneration at $7 \mathrm{~mol} \cdot \ell^{-1}$, this is a significant factor influencing the cost of the removal process as well as waste disposal. The Freundlich isotherm was found to best describe the experimental data, suggesting that adsorption occurred on a heterogeneous surface. The pseudo secondorder model was found to explain the adsorption kinetics most effectively. This model and the results of the thermodynamic study showed that As adsorption occurred via chemisorption. The study has shown, overall, that PCPEI can be used for the abstraction of As from wastewaters and can perform comparably to other remediation techniques.

\section{REFERENCES}

AHAMED IS, GHONAIM AK, ABDEL HAKIM AA, MOUSTAFA MM and KAMAL EL-DIN AH (2008) Synthesis and characterization of some polymers for removing of some heavy metal ions of industrial wastewater. J. Appl. Sci. Res. 4 1946-1958.

AKPOR OB and MUCHIE M (2010) Remediation of heavy metals in drinking water and wastewater treatment systems: Processes and applications. Int. J. Phys. Sci. 5 1807-1817.

ANTURES W, LUNA A, HENRIQUES C, and COSTA A (2003) An evaluation of copper biosorption by a brown seaweed under optimized conditions. Electron. J. Biotechnol. 6 174-184.
BHATTACHARYA AS, MANDAL SN and DAS SK (2007) Bioaccumulation of zinc, copper and lead in upper stretch of Gangetic West Bengal. Trends Appl. Sci. Res. 2 492-499.

CARVALHO K and MARTIN D (2001) Removal of aqueous selenium by four aquatic plants. J. Aquat. Plant Manage. 39 33-36.

FREUNDLICH HA (1926) Adsorption. Phys. Chem. 7 57-64.

GUPTA V, JAIN C, ALI I, SHARMA M and SAINI VK (2003) Removal of cadmium and nickel from wastewater using bagasse fly ash a sugar industry waste. Water Res. 37 4038-4044.

HAMDAOUI O and NAFFRECHOUX E (2007) Modelling of adsorption isotherms of phenol and chlorophenols onto granular activated carbon part I. Two parameter models and equations allowing determination of thermodynamic parameters. J. Hazardous Mater. 174 381-394.

HERMOND H and FECHNER-LEVY EJ (2000) Chemical Fate and Transport in the Environment. Academic Press, San Diego.

KLEKAMP A and UMBACH E (1993) Physisorption on an epitaxial $\mathrm{NaCl}(100)$ double-layer: $\mathrm{SF}_{6}$ and xenon. Surf. Sci. 284 291-304.

LEROY D, MARTINOT L, MIGNONSIN P, STRIVAY D, WEBER G, JEROME C and JEROME R (2003) Complexation of uranyl ions by polypyrrole doped by sulfonated and phosphonated polyethylenimine. J. Appl. Polym. Sci. 88 352-359.

LI C, CHENG K, CHOO K and YEN W (2008) Polyelectrolyte enhanced ultrafiltration (PEUF) for the removal of Cd(II): Effects of organic ligands and solution $\mathrm{pH}$. Chemosphere 72 630-635.

LIU JF, ZHAO ZS and JIANG GB (2008) Coating Fe3O4 magnetic nanoparticles with humic acid for high efficient removal of heavy metals in water. Environ. Sci. Technol. 42 6949-6954.

MADONI P and ROMEO MG (2005) Acute toxicity of heavy metals towards freshwater ciliated protists. Environ. Pollut. 141 (1) 1-7.

MOHAN D and PITTMAN C (2007) Arsenic removal from water/ wastewater using adsorbents - a critical review. J. Hazardous Mater. 142 1-53.

ÖZCAN A, ÖNCU E and ÖZCAN A (2006) Kinetics, isotherm and thermodynamic studies of adsorption of Acid Blue 193 from aqueous solutions onto natural sepiolite. J. Colloids Surf. 277 90-97.

RUPARELIA J, DUTTAGUPTA S, CHTTERJEE A and MUKHERJI S (2008) Potential of carbon nanomaterials for removal of heavy metals from water. Desalination 232 145-156.

SAAD D, CUKROWSKA E and TUTU H (2011) Development and application of cross-linked polyethylenimine for trace metal and metalloid from mining and industrial wastewaters. Toxicol. Environ. Chem. 93 914-924.

SAAD D, CUKROWSKA E and TUTU H (2012) Phosphonated crosslinked polyethylenimine for selective removal of uranium ions from aqueous solutions. Water Sci. Technol. 66 122-129.

SAAD D, CUKROWSKA E and TUTU H (2011) Sulfonated crosslinked polyethylenimine for selective removal of mercury from aqueous solutions. Toxicol. Environ. Chem. 94 1916-1929.

SAUER N, EHLER D and DURAN B (2004) Lead extraction from contaminated soil using water-soluble polymers. J. Environ. Eng. $130585-588$.

SAVAG N and DIALLO M (2005) Nanomaterials and water purification: opportunities and challenges. J. Nanoparticle Res. 7 331-342.

TUTU H, CUKROWSKA E, MCCARTHY T, HART R and CHIMUKA L (2009) Radioactive disequilibrium and geochemical modelling as evidence of uranium leaching from gold tailing dumps in the Witwatersrand Basin. Int J. Environ. Anal. Chem. 89 687-703. 
http://dx.doi.org/10.4314/wsa.v39i2.9 Available on website http://www.wrc.org.za

ISSN 0378-4738 (Print) = Water SA Vol. 39 No. 2 April 2013 ISSN 1816-7950 (On-line) = Water SA Vol. 39 No. 2 April 2013 